\title{
Improved QPR Power Controller With Harmonic Compensator For Wind Grid-Connected Inverter
}

\author{
Sun Jian ${ }^{1 *}$ Eid Amin ${ }^{1}$ Zhang Yunning ${ }^{1}$ \\ ${ }^{1}$ College of Electrical Engineering and New Energy, China Three Gorges University, Yichang 443000, China \\ * E-mail of the corresponding author: engr_eidamin@yahoo.com
}

\begin{abstract}
The grid-connected inverter plays an important role in wind turbine grid-connected power generation system. The performance of inverter control strategy directly affects the grid-connected current quality. For quasi-proportional resonant(QPR) control, the output signal step of controller exists owing to the input signal step, and the grid current will be distorted by the low-frequency noise in the input signal. In order to solve these problems, the performance of quasi-PR control should be improved, so a method of constructing quasi-PR controller with two degrees of freedom is adopted, by which the improved controller can effectively suppress the influence of the step and low-frequency noise in the input signal on the grid-connected current. The improved controller is simulated on MATLAB, and the results show that the applied method can effectively improve the property of the existing problems of quasi-QPR controller and the quality of grid-connected current.
\end{abstract}

Keywords: Grid-connected inverter, Harmonic compensator, Matlab/Simulation, 2-DOF,QPR.

DOI: $10.7176 / \mathrm{CTI} / 8-05$

\section{Introduction}

In the recent world demands and use of electricity generation take a diversion towards renewable energy source because of large availability, clean environment, and less pollution. The daily increasing power and energy demands have promoted the development of wind power energy system. At the grid side for synchronization of power generated by the wind turbine and power demanded by grid station, we need to install a grid-connected inverter with wind power generators which can satisfy stringent control requirements under steady-state and transient conditions [1-2]. The controlling technologies and methods of connected grids from renewable energy sources have obtained increasingly attention of the researchers. How to enhance the quality of grid-side current and compensate the harmonics has become research goal of renewable energy field[3]. In recent years proportional-resonant (PR)control is the most famous current controlling technique for grid-connected systems [4-7], mostly used to remove the tracking error during the regulating of the sine wave signal. For the PR control, controller and filters can easily implement selective harmonics without desirable computational resources. However, the implementation of the ordinary PR algorithm requires very high precision hardware system and it is not friendly interface to grid frequency offsets, also difficult to apply in practice [8]. The 3-phase LCL-type grid-connected inverter in [9] is provide the fuzzy algorithm for the Quasi-PR control, which consists of two loops, for the capacitor current "Inner feedback control loop" for the grid side current "Outer QPR control loop" respectively. For the regulating the QPR controller the researcher also used self-tuning of the fuzzy parameters and high performance is obtained. The Quasi-PR current Controller is examined for capacitive coupling (CC) grid-connected inverter system and in contradiction with the PI current controller, but the quasi-PR controller decrease the steady-state error[10]. It also produces a voltage reference for applying the carrier-based PWM to boost the quality of the waveform. In this article the improved quasi-PR algorithm with harmonic compensator is designed to overcome shortcomings of QPR and eliminate the impact of harmonics frequencies on grid-connected current. The design procedure of QPR current controller and selective harmonics compensation method has been applied for $3^{\text {rd }}$, 5th, and $7^{\text {th }}$ harmonics using Matlab tools.

\section{Grid-connected inverter based the QPR controller with harmonic compensator}

For the selected resonant frequency, the ordinary PR controller has an infinite gain and zero steady state error for the specific AC signal. The bandwidth of the signal is very narrow so in this paper we adopt the Quasi-PR controller. The block diagram of grid-connected inverter based the QPR controller with harmonic compensator is shown in figure 1 . The QPR is the resonance term used to achieve $50 \mathrm{~Hz}$ tracking of the baseband signal. 
Harmonic compensator is the harmonic suppression and the system can be used for low-order (mainly $3^{\text {th }}, 5^{\text {th }}, 7^{\text {th }}$ ) multiplier signals. Sampling the inverter current, the L-type filter is used.

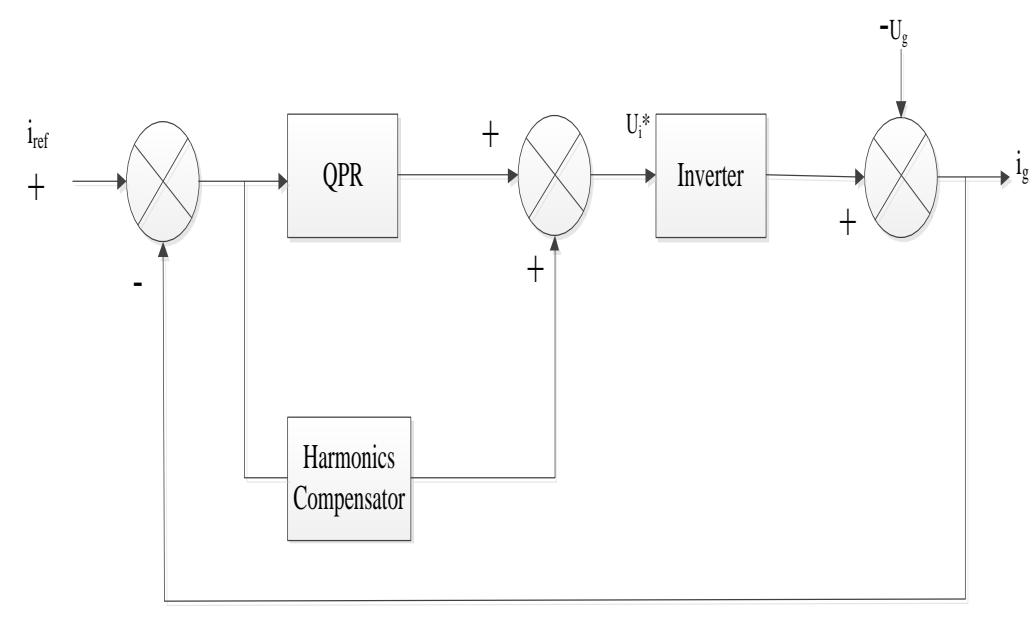

Figure 1.The QPR current controller with harmonic compensator

The transfer function of the QPR is given in equation (1).

$$
G_{Q P R}(s)=k_{p}+\frac{2 k_{i} w_{c} s}{s^{2}+2 w_{c} s+w_{0}^{2}}
$$

In the equation (1), $k_{p}$ is proportional coefficient and $k_{i}$ is integral coefficient, $w_{0}$ is resonant frequency, whereas $w_{c}$ is the cut-off frequency.

The transfer function of harmonic compensator $G_{H}(\mathrm{~s})$ is shown in equation (2)

$$
G_{H}(s)=+\sum_{n=3}^{h} \frac{2 k_{n} w_{c} s}{s^{2}+2 w_{c} s+\left(n w_{0}\right)^{2}}
$$

In Figure $1, i_{\text {ref }}$ is the reference current with the same frequency and phase as the network voltage, $i_{g}$ is the grid-connected current, $u_{g}$ is the grid voltage, The equivalent transfer function of the inverter $G_{d}(\mathrm{~s})$, and transfer function of the filter $G_{f}(\mathrm{~s})$, is shown in equation (3) and equation (4) respectively.

$$
G_{d}(s)=\frac{k_{P W M}}{T_{P W M} s+1}
$$

Where: $T_{P W M}$ is the switching period of the inverter; $k_{P W M}$ is the equivalent gain of the inverter to the switching function. The transfer function of L-type inductor filter in the system is:

$$
G_{f}(s)=\frac{1}{s L_{g}+R_{g}}
$$

Where: $L g$ is the grid side filter inductance, $R g$ is the grid side equivalent internal resistance. According to Figure 1, the control system model of the grid-connected inverter is used to drive the system for Open loop transfer function and closed loop under the grid voltage disturbance, the transfer functions are shown in equations (5) to (7) respectively.

$$
G_{\text {Open }}(s)=G_{Q P R}(s) G_{d}(s) G_{f}(s)
$$




$$
\begin{gathered}
G_{R D}(s)=\frac{G_{f}(s)}{1+G_{\text {Open }}(s)} \\
G_{\text {Close }}(s)=\frac{G_{\text {Open }}(s)}{1+G_{\text {Open }}(s)}
\end{gathered}
$$

According to equation (6), the grid voltage $u_{g}$ is connected to the grid-connected current disturbance. The Bode diagram of $G_{R D}(\mathrm{~s})$ is shown in Figure 2.
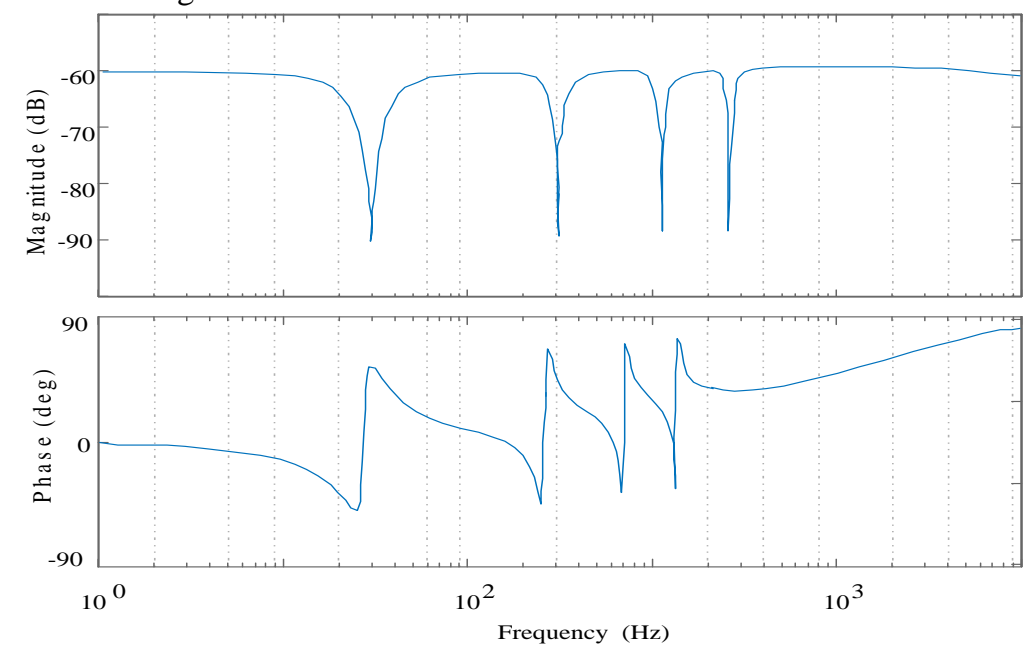

Figure 2. Bode diagram of $G_{R D}(\mathrm{~s})$

According to the equation (7) bode diagram of the closed-loop transfer function of the system is shown in figure 3.
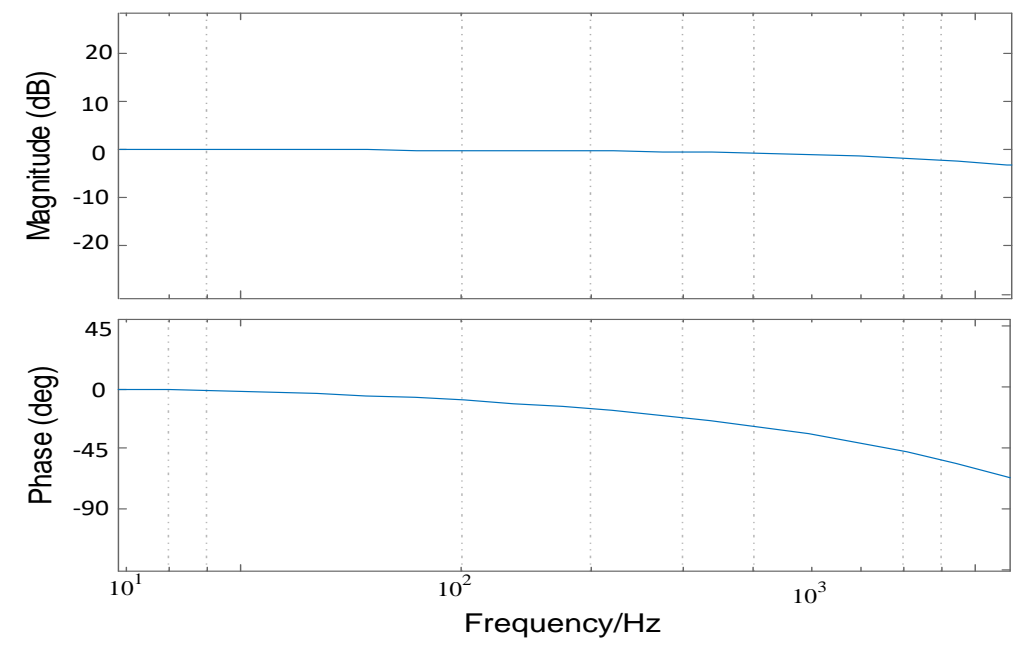

Figure 3. Close loop Bode diagram of the Closed- loop System with QPR controller

In figure 3, the obtained results shows that $G_{\text {close }}(s)$ has the unity gain with null phase shifting for the basic frequency with chosen parameters. The magnitude response change in the region of zero at low frequency range when PI controller is used [10]. Increasing the PI controller proportional gain may affect the magnitude response toward zero. Anyhow high gain may cause the function of the control system. The ability of current tracking is raised when the QPR controller is used. Steady state current tracking error is minimized by using QPR controller according to the response in Figure 3. Therefore QPR is more appropriate Controller. 


\section{The construction of 2-DOF QPR controller and Characteristic analysis}

\subsection{Construction of a 2-DOF QPR controller}

Two Degrees of Freedom Active Damping Technique is developed for Filter-Based Grid-Connected PV Systems[11]. The one degree of freedom is transformed into the two degrees of freedom controller by decomposition of the input signal and reformation the structure of one-degree of freedom controller, in order to achieve the goal of double-optimal tracking performance and harmonics suppression performance for given values. In reference [12] the controlling layout is Adaptive linear element strategy, which is used to remove positive sequence basic frequency elements of the grid by tracing the unit vectors along with tuning of the weights. The structure of the modified controller system is shown in Figure 4.

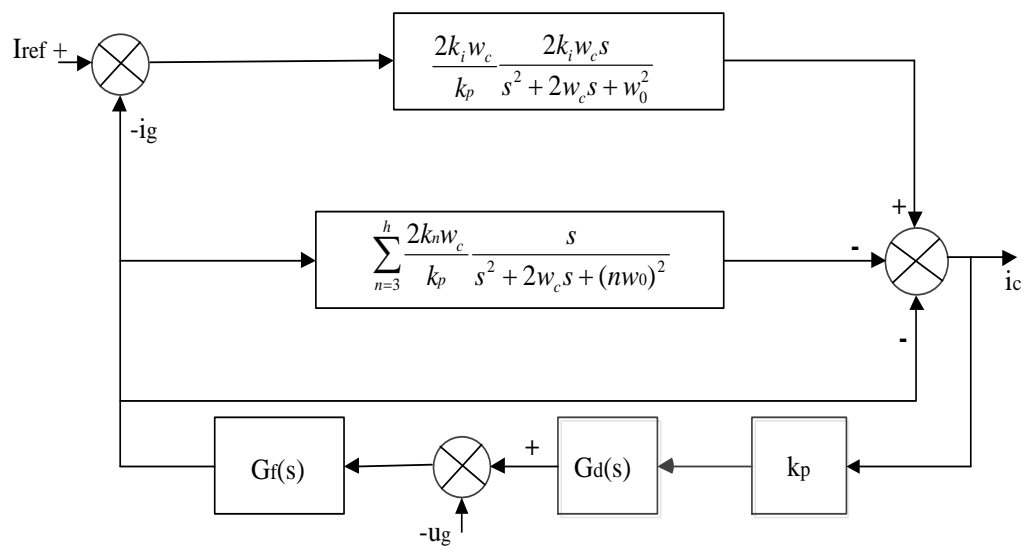

Figure 4. The modified model of QPR control system

The closed-loop transfer function of the improved system is shown in equation (8). The open loop transfer function is the same as the unmodified quasi PR control.

$$
G_{\text {Close }}(s)=\frac{G_{\text {Open }}(s)}{1+G_{\text {Open }}(s)} \times \frac{\frac{2 k_{i} w_{c} s}{s^{2}+2 w_{c} s+w_{0}^{2}}}{k_{p}+\frac{2 k_{i} w_{c} s}{s^{2}+2 w_{c} s+w_{0}^{2}}+\sum_{n=3}^{h} \frac{2 k_{n} w_{c} s}{s^{2}+2 w_{c} s+\left(n w_{0}\right)^{2}}}
$$

\subsection{Analysis of the controller's anti-low frequency noise interference characteristics}

According to the improved system control model (Figure.4), The system's reference input signal and the feedback signal of grid-connected current applied to different controllers respectively, so that the tracking of fundamental frequency signal and the suppression of low-frequency noise can be separately controlled to achieve the tracking of $50 \mathrm{~Hz}$ signal and the suppression of low-order harmonics. The Bode diagram of the closed-loop transfer function of the system is obtained from the control model and equation (8), as shown in Figure 5. 

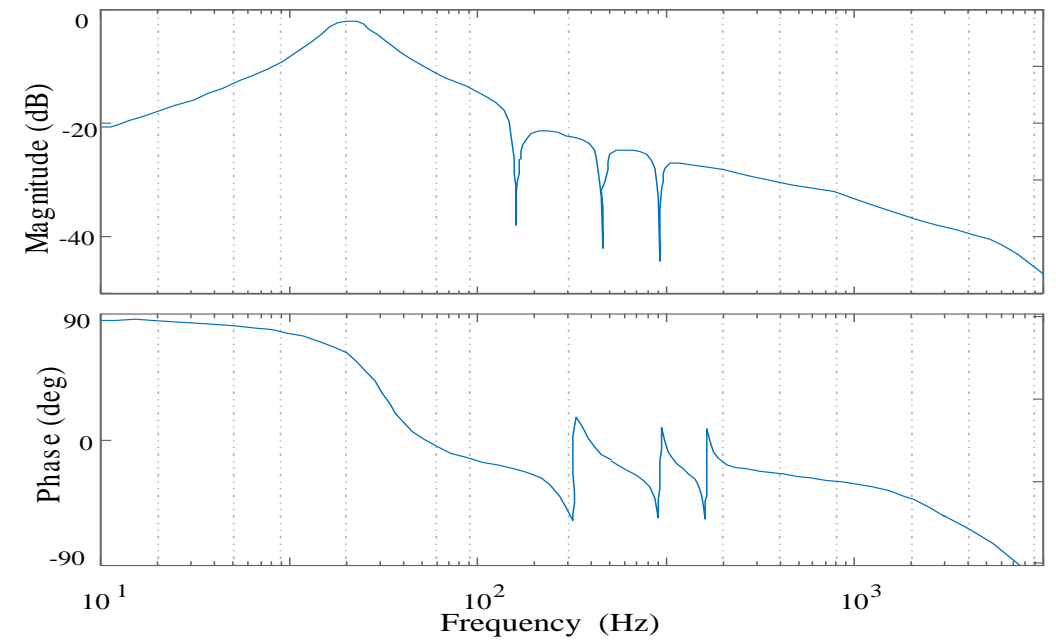

Figure 5. Bode Diagram of Closed-Loop Transfer Function for

An Improved Quasi-PR Controller System

As can be observed from Figure 5, the gain of the system is 1 at $50 \mathrm{~Hz}$ and very small at $150,250 \mathrm{and} 350 \mathrm{~Hz}$, which shows that the system has tracking ability for components at $50 \mathrm{~Hz}$ and suppressing ability for other low-order harmonic components. Compared with the traditional quasi-PR controller, the system can track signals at 50,150, 250 and $350 \mathrm{~Hz}$. The improved QPR current controller can suppress the low-frequency noise interference very well.

\section{Analysis of Controller Step Suppression Characteristics}

The output of the traditional quasi-PR controller cannot suppress the step signal because the input step signal will directly act on the proportional part of the controller. After the improvement of the controller, the proportional part is moved back and stepped. The signal does not directly act on the proportional part but on the resonant part. When the step reference input signal is loaded into the resonant part, the output signal only has a component at the resonant frequency and no step will occur. The simulation model of the quasi-PR controller with two degrees of freedom is built. The simulation results are shown in Figure 6 where 1- shows reference Input Signal and 2-shows the Improved Controller Output Signal. From figure 6, it can be seen that the output of the controller is almost zero to step input, which shows that the improved QPR is able to overcome the shortcoming of the traditional quasi PR controller, and is more suitable for wind power grid-connected control.

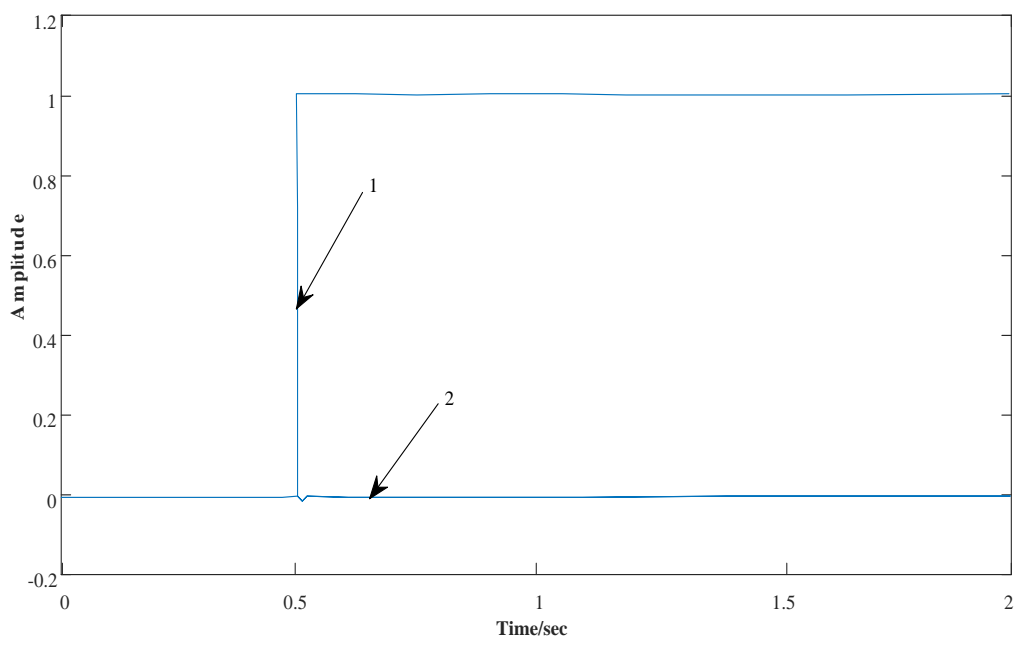

Figure 6. Step Response of Improved QPR Controller 
In the simulation, a certain amount of third, fifth and seventh harmonics are applied into the power grid and set the reference input signal from step 4 to step 7 . Figures 7 to 9 are grid-connected current waveforms controlled by 2-DOF PR current controller and 2-DOF QPR current controller respectively.

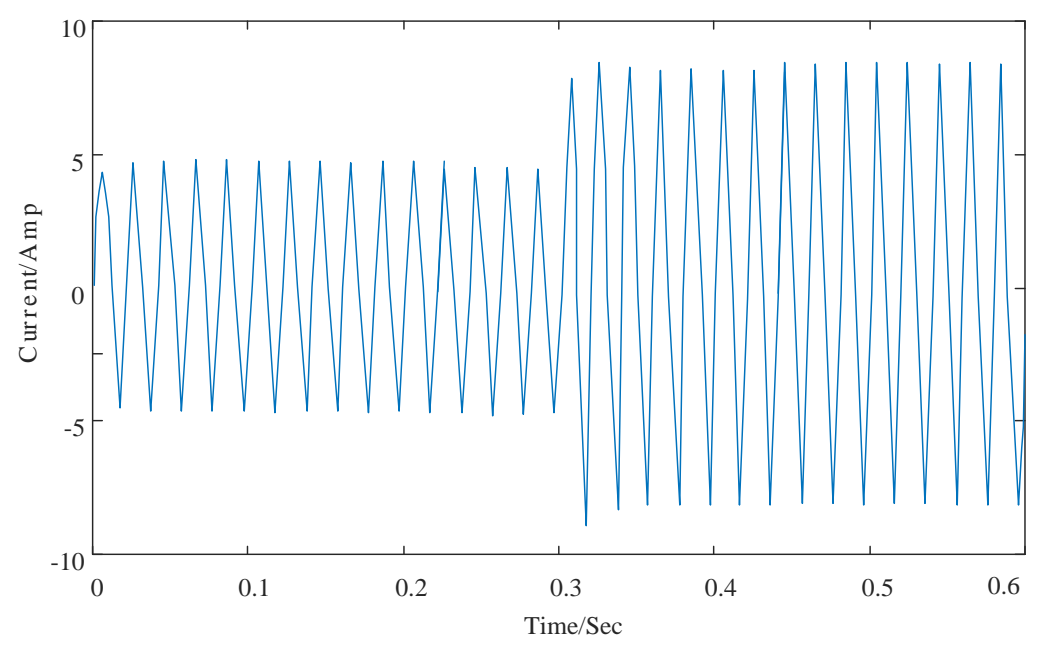

Figure 7. Grid-connected current waveform when the step occurs in an input signal of QPR control

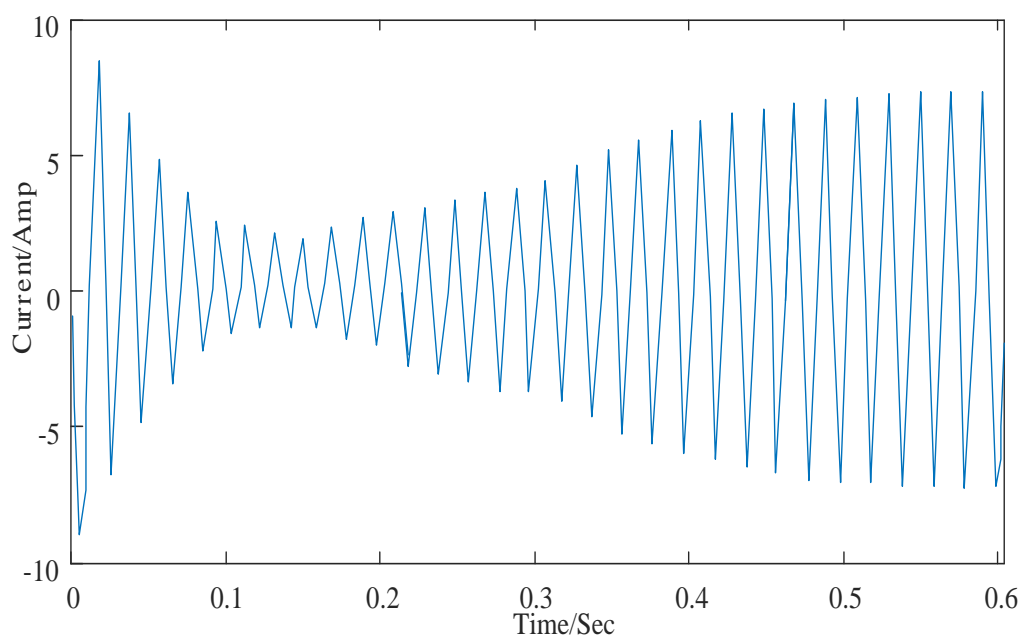

Figure 8. Grid-connected current waveform when the step occurs in 2-DOF PR control input signal 


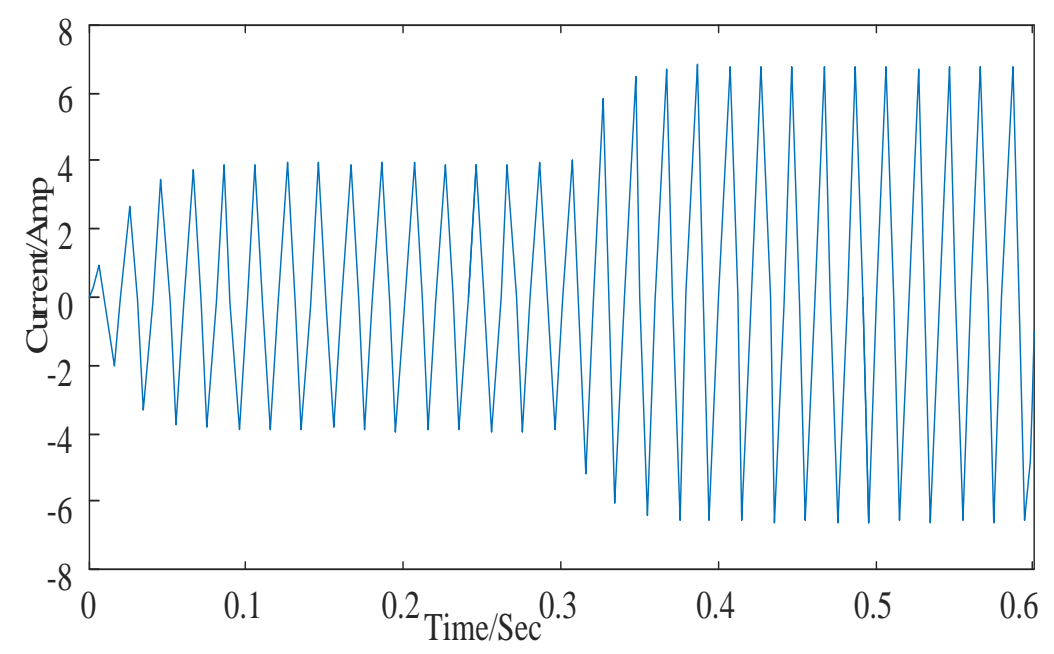

Figure 9. Grid-connected current waveform when the step occurs in an input signal of 2-DOF QPR control

Comparing the simulation waveforms in the above three cases, it can be seen that, when the amplitude of the reference input current takes a stepped. In Figure.7 the current waveform controlled by a quasi-PR current controller is distorted, which will have an impact on the grid and interfere with the stable operation of the power grid. In Figure 8 the current waveform controlled by a 2-DOF PR current controller is somewhat distorted at the beginning and takes a long time to reach stability. When the input signal step occurs, the grid-connected current does not step, but the speed of tracking the reference current is slow and took about 7 cycles. In Figure. 9 the grid-connected current waveform controlled by a 2-DOF quasi-PR current controller does not step when the input reference signal steps. The reference current can be tracked after 2 cycles with no apparent distortion. By comparison, the 2-DOF quasi-PR controller is the best choice for single-phase grid-connected current control. It can seem that the 2-DOF quasi-PR controller tracks the voltage capability of a power network better than the 2-DOF PR controller. After the grid-connected current is stable, the simulation diagram in the range of $0.505 \sim 0.545 \mathrm{~s}$ is used to compare the effect of the two parallel grid-connected current tracking networks voltage. As shown in Figure10, the grid-connected current has been increased 10 times for the convenience of observation. From Figure 10, it can be seen that there is a certain phase error between grid-connected current and voltage under the control of 2-DOF QPR controller, and it can achieve the same frequency and phase with the grid voltage very well. The existence of phase difference reduces the power factor of grid-connected inverters.

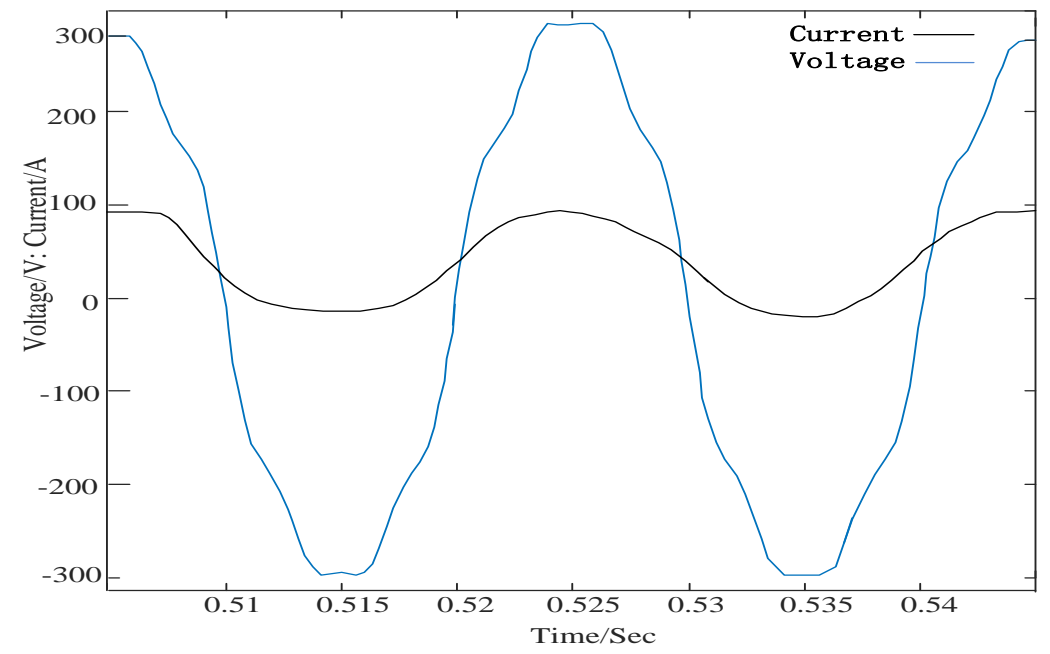

Figure 10. Grid-connected Voltage and Current under 2-DOF Quasi-PR Control

There is no phase deviation which indicates that the QPR grid connected controller current tracking capability is good and more conducive to improve the grid-connected power factor. 


\section{Conclusion}

By analyzing the theory and performance of improved QPR controller and the simulation results of MATLAB it can be proved that 2DOF quasi-PR controller has a strong ability to suppress the harmonics of power grid without PLL. It also suppresses the step of the output signal and it can effectively reduce the instantaneous impact of reference current step on the power grid. When this control mode is adopted, the grid-connected current can be quickly tracked the change of the reference current amplitude, and keep the same frequency and phase with the network voltage and high-quality grid-connect current is guaranteed.

\section{Acknowledgement}

This work was supported in part by National Natural Science Foundation of China (Nos.:61603212) and also I would like to demonstrate my wholeheartedly gratitude to my MS supervisor Dr. Sun Jian for the prolonged help, encouragement and immense knowledge for my study and research.

\section{References}

Zameer Ahmad, S.N.Singh.(2018).Improved modulation strategy for single-phase grid-connected transformerless PV inverter topologies with reactive power generation capability.

Daniel Zammit,Cyril Spiteri Staines,Maurice Apap, John Licari.(2017).Design of PR current control with selective harmonic compensators using Matlab.

Zhao, Q., Ye, Y., Xu, G., Zhu, M.(2016). Improved repetitive control scheme for grid-connected inverter with frequency adaptation, IET Power Electronics, Vol.9, No.5, 883-890.

Liu, Y., Bai, R., Wang, D., Ma, W., Wang, L. (2014). Proportional-resonant control method of three-phase grid-connected inverter. The 26th Chinese Control and Decision Conference (2014 CCDC), 4797- 4800.

Cai, H., Wei, W., Peng, Y., Hu, H. (2014). Fuzzy proportional-resonant control strategy for three-phase inverters in islanded micro-grid with nonlinear loads, IEEE International Conference on Fuzzy Systems, 6-11.

Vidal, A., Freijedo, F. D., Yepes, A. G., Fernandez-Comesana, P.(2013). Assessment and optimization of the transient response of proportional-resonant current controllers for distributed power generation systems, IEEE Transactions on Industrial Electronics, Vol.60, No.4, 1367-1383.

DehghaniTafti,H., Maswood,A. I.,Ukil,A. O.,Gabriel,H. P.,Ziyou, L.(2014). NPC photovoltaic grid-connected inverter using proportional resonant controller, 2014 IEEE PES Asia-Pacific Power and Energy Engineering Conference (APPEEC), 1-6.

An Jing.(2014). Research on low power photovoltaic grid-connected inverter [D]. Beijing: Beijing traffic University.

Xiangjun Duan,Hannian Zhang. (2017).Quasi-Proportional Resonant Control of the LCL-Type Grid-Connected Inverter Based on Fuzzy Control and Self-Tuning of Fuzzy Parameters, IEEE.

Ye, T., Dai, N. Y., Lam, C. S., Wong, M. C. (2015).Analysis, design and implementation of a quasi-proportional-resonant controller for multifunctional capacitive-coupling grid-connected inverter, IEEE Energy Conversion Congress and Exposition (ECCE), 2506- 2513.

Hanif M, Vinod Khadkikar, Weidong Xiao, Jams L. Kirtley. (2014). Two Degrees of Freedom Active Damping Technique for Filter-Based Grid Connected PV Systems[J]. Industrial Electronics IEEE Transactions.

Dipesh Kumar Karmakar,Laxman Dasari,N.G.S Raju.(2015).Stand-Alone Wind Power Generation using Adaline Based Integrated Electronic Load Controller.Control Theory and Informatics www.iiste.org ISSN 2224-5774 (Paper) ISSN 2225-0492 (Online) Vol.5, No.6.

Dipesh Kumar Karmakar, Kapavarapu M R Phani Swaroop, N.G.S Raju.(2015)” Performance of Wind Farm Employing Type-4 Wind Turbine with D-Statcom," Control Theory and Informatics ISSN 2224-5774 (Paper) ISSN 2225-0492 (Online) Vol.5, No.5. 
Rekha,Manmohan Kumar,A.K.Singh.(2014).Fuzzy Controlled SVC for Reactive Power Control of Long Transmission Lines.Control Theory and Informatics www.iiste.org ISSN 2224-5774 (Paper) ISSN 2225-0492 (Online) Vol.4, No.7.

Chun-Feng Lu, Chia-Hung Hsu, Chia-Feng Juang.(2013).“Coordinated Control of Flexible AC Transmission System Devices Using an Evolutionary Fuzzy Lead-Lag Controller With Advanced Continuous Ant Colony Optimization" IEEE Transactions. 